\title{
Neuromuscular transmission modulation by adenosine upon aging
}

\author{
Paula A. Pousinha ${ }^{\mathrm{a}, \mathrm{b}}$, Alexandra M. Correia ${ }^{\mathrm{a}, \mathrm{b}, \mathrm{c}}$, Ana M. Sebastião ${ }^{\mathrm{a}, \mathrm{b}, *}$, Joaquim A. Ribeiro $^{\mathrm{a}, \mathrm{b}}$ \\ ${ }^{a}$ Institute of Pharmacology and Neurosciences, Faculty of Medicine, University of Lisbon, Portugal \\ ${ }^{b}$ Unit of Neurosciences, Institute of Molecular Medicine, University of Lisbon, Portugal \\ ${ }^{c}$ Museu Nacional de História Natural e da Ciência, University of Lisbon, Portugal
}

Received 17 May 2011; received in revised form 12 January 2012; accepted 19 January 2012

\begin{abstract}
In infant rats adenosine $\mathrm{A}_{2 \mathrm{~A}}$ receptor-mediated modulation of neuromuscular transmission predominates over $\mathrm{A}_{1}$ receptor-mediated neuromodulation. We investigated whether aging affects this $\mathrm{A}_{2 \mathrm{~A}} / \mathrm{A}_{1}$ receptor balance. Evoked (EPPs) and miniature end plate potentials (MEPPs) were recorded from single fibers of (weeks-old) infant (3-4), young adult (12-16), older (36-38), and aged (80-90) male rat-diaphragm. The non $\mathrm{A}_{1} / \mathrm{A}_{2 \mathrm{~A}}$ selective agonist, 2-chloroadenosine (CADO; $30 \mathrm{nM}$ ) and the adenosine kinase inhibitor, iodotubericidin (ITU; $10 \mu \mathrm{M}$ ) increased mean amplitude and quantal content of EPPs in infant, young adult, and older adult rats, but not in aged rats. The facilitatory effects were prevented by the $\mathrm{A}_{2 \mathrm{~A}}$ receptor antagonist, ZM241385 (50 nM) and mimicked by the $\mathrm{A}_{2 \mathrm{~A}}$ receptor agonist, CGS21680 (10 nM). The $A_{1}$ receptor agonist, 6-cyclopentyladenosine (CPA; $\left.100 \mathrm{nM}\right)$, decreased EPPs amplitude in all age groups. It is concluded that aging differently influences adenosine $\mathrm{A}_{1}$ receptor and $\mathrm{A}_{2 \mathrm{~A}}$ receptor-mediated presynaptic modulation of neuromuscular transmission, so that the facilitatory influence decreases upon aging, whereas the inhibitory influence remains unchanged in aged animals. The reduction of adenosine $\mathrm{A}_{2 \mathrm{~A}}$ receptors upon aging may contribute to the age-related changes in neuromuscular function.
\end{abstract}

(C) 2012 Elsevier Inc. All rights reserved.

Keywords: Aging; Adenosine; Adenosine receptors; Neuromuscular junction; Neuromuscular transmission; EPPs and MEPPs

\section{Introduction}

It is well established that adenosine decreases the amplitude and the quantal content of evoked endplate potentials (EPPs) at the neuromuscular junctions from several species, including adult rats (Ginsborg and Hirst, 1972) and frogs (Ribeiro and Walker, 1975). It is also known that in the same motor nerve terminal, both inhibitory adenosine $A_{1}$ receptors and excitatory adenosine $\mathrm{A}_{2 \mathrm{~A}}$ receptors coexist, modulating the evoked release of acetylcholine (Correiade-Sá et al., 1991). The way in which adenosine is able to achieve a balance in the control of neurotransmission depends on the extracellular concentration of the nucleoside, which subsequently depends on extracellular adenosine generation and inactivation (via cellular uptake and/or ex-

\footnotetext{
* Corresponding author at: Institute of Pharmacology and Neurosciences, Faculty of Medicine, Av. Prof. Egas Moniz, 1649-028 Lisboa, Portugal. Tel.: +35121798 5183; fax: +35121799 9454 .

E-mail address: anaseb@fm.ul.pt (A.M. Sebastião).
}

tracellular deamination) (Sebastião and Ribeiro, 1988). At the rat neuromuscular junction extracellular adenosine can be originated by transport-mediated release (Cunha and Sebastião, 1993), in parallel with its formation from released adenosine triphosphate (ATP) (Smith, 1991). Recently, we described that at the motor nerve endings of infant rats low extracellular concentrations of adenosine activate both $\mathrm{A}_{2 \mathrm{~A}}$ and $\mathrm{A}_{1}$ receptors, but activation of facilitatory $\mathrm{A}_{2 \mathrm{~A}}$ receptors predominates over inhibitory $\mathrm{A}_{1}$ receptors (Pousinha et al., 2010).

In the central nervous system, the neuromodulatory action of adenosine and the expression of its membrane receptors change with age (see Diógenes et al., 2011; Sebastião and Ribeiro, 2009). So, it was considered of interest to investigate the role of adenosine at the neuromuscular junction, as a function of age, looking at the relative importance of adenosine $A_{1}$ receptors vis-a-vis adenosine $A_{2 A}$ receptors. The results now reported show that excitatory $\mathrm{A}_{2 \mathrm{~A}}$ receptor functioning at the motor nerve terminal decreases with aging even disappearing in aged rats, whereas 
inhibitory $A_{1}$ receptor action is preserved throughout aging. These age-dependent changes in the balance of excitatory over inhibitory neuromodulation may therefore contribute to the age-related decline in neuromuscular transmission.

\section{Methods}

\subsection{Animals}

The experiments were performed on isolated preparations of the phrenic nerve-diaphragm from male Wistar rats obtained from Harlan Interfauna Iberia, SL (Barcelona). Four groups of rats were used: infant (3-4 weeks old), young adult (12-16 weeks old), older adult (36-40 weeks old), and aged (70-80 weeks old). The animals, handled according to European Community guidelines and Portuguese Law on animal care, were killed by decapitation under halothane anesthesia. A strip of the left hemidiaphragm was isolated together with the phrenic nerve and was mounted in a $3 \mathrm{~mL}$ Perspex chamber through which the solutions flowed continuously at a rate of $3 \mathrm{~mL}$ per minute via a roller pump. The solutions were at room temperature $\left(22{ }^{\circ} \mathrm{C}-23{ }^{\circ} \mathrm{C}\right)$. The bath volume was kept constant by suction. Solutions were changed by transferring the inlet tube of the pump from 1 flask to another. This involved a minimum of disturbance to the preparation and allowed prolonged recording from the same fiber with many solution changes. The change-over times in the figures of this report indicate the times at which the inlet tube of the pump was transferred to a new solution. Whenever testing the effect of a drug in the presence of an adenosine receptor (AR) antagonist, superfusion of the antagonist started at least 45 minutes before addition of another drug to the solution. In all cases, the superfusion of the drugs was only initiated when the recordings were considered stable by online analysis of the results. When used, adenosine deaminase (ADA) was added to the preparations at least 30 minutes before addition of the adenosine receptor agonist in its presence.

\subsection{Electrophysiology recordings}

Evoked EPPs and miniature end-plate potentials (MEPPs) were recorded in the conventional way (Fatt and Katz, 1951), with intracellular electrodes filled with $\mathrm{KCl}(3 \mathrm{M})$ and 10-20 $\mathrm{M} \Omega$ resistance, inserted in the motor end plate. The reference electrode was an $\mathrm{Ag}-\mathrm{AgCl}$ pellet. The nerve was stimulated supramaximally (rectangular pulses of $20 \mu \mathrm{s}$ duration applied once every 2 seconds) through a suction electrode. Individual EPPs, as well as the resting membrane potential of the muscle fiber, were continuously monitored. Muscle fibers with a resting membrane potential less negative than $-60 \mathrm{mV}$, were rejected. Throughout the experiment, EPPs and the resting membrane potential were continuously monitored and digitally stored on a personal computer with the Clampex program (pCLAMP 10; Axon Instruments, Foster City, CA, USA). The results were later analyzed off-line and each 60 consecutive EPPs were aver- aged. The $n$ used in statistical analyses was number of experiments, which corresponds to a single neuromuscular junction per preparation/animal. The neuromuscular junctions from which data that was considered for further analysis was selected by the following parameters: the stability of the resting membrane potential, which could not spontaneously vary by more than $5 \%$ while assaying a drug effect, the initial value of the membrane potential, which ranged between -60 and $-80 \mathrm{mV}$, and the initial amplitude of EPPs, which ranged between 2 and $4 \mathrm{mV}$. MEPPs were sampled and stored before the application of the drugs at 16 and 30 minutes and in some experiments 46 minutes, after starting drug perfusion. Later, the samples were analyzed off-line. MEPPs were detected by an event detection protocol. The threshold for detection of MEPPs was set at the level of $0.25 \mathrm{mV}$ of amplitude and $2 \mathrm{~ms}$ of duration to prevent the contamination of the signal with electric noise. Mean MEPP frequency was measured by counting the number of MEPPs acquired in gap free mode for 100 -second periods, at the following times: -10 minutes (before adding the drug), 0 minutes (immediately before addition), and 30 minutes after starting drug perfusion. The values were only considered for posterior analysis whenever MEPP frequency at -10 minutes and 0 minutes did not differ by more than $5 \%$. The mean amplitude of MEPPs was calculated considering the average of the mean amplitude of 100 consecutive MEPPs. In the calculation of the mean amplitude of the MEPPs, the occasional "giants" (above $1 \mathrm{mV}$ ) were neglected, because it has been shown that they do not contribute to the components of evoked release (Menrath and Blackman, 1970). A change in MEPP frequency that was not accompanied by a change in MEPP amplitude was interpreted as a change in spontaneous transmitter release (see Katz, 1969). Quantal contents were estimated as the ratio of the average evoked response to the average amplitude of the MEPPs recorded during the same period.

\subsection{Drugs}

The bathing solution contained (mM): $\mathrm{NaCl} 117, \mathrm{KCl} 5$, $\mathrm{NaHCO}_{3} 25, \mathrm{NaH}_{2} \mathrm{PO}_{4}$ 1.2, glucose $11, \mathrm{CaCl}_{2} 2.5, \mathrm{MgCl}_{2}$ 1.2. It was continuously gassed with $95 \% \mathrm{O}_{2}$ and $5 \% \mathrm{CO}_{2}$ $\left(\mathrm{pH}\right.$ 7.4) and kept at room temperature $\left(22{ }^{\circ} \mathrm{C}-25{ }^{\circ} \mathrm{C}\right)$. Muscle twitches were prevented by increasing the bath concentration of $\mathrm{Mg}^{2+}$ to $19 \mathrm{mM}$.

Drugs used were: adenosine, 2-chloroadenosine (CADO), ADA (type VI, $1803 \mathrm{U} \mathrm{mL}^{-1}$, EC 3.5.44), 2-p-(2-carboxyethyl) phenethylamino]-5'-N-ethylcarboxamido adenosine hydrochloride (CGS-21680), 1,3-dipropyl-8-cyclopentylxanthine (DPCPX), 5'-iodotubericidin (ITU), and d-tubocurarine chloride were obtained from Sigma-RBI (St. Louis, MO, USA); 4-(2-[7-amino-2-(2-furly)[1,2,4] triazolo[2,3a] $[1,3,5]$ triazin5ylamino] ethyl) phenol (ZM241385) was supplied by Tocris Cooksonhem (Ballwin, MO, USA). Stock solutions (5 mM) of CGS21680, 6-cyclopentyladenosine (CPA), DPCPX, ZM241385, and ITU were prepared in dimethyl sulfoxide (DMSO). Aliquots of these stock solutions 
were kept frozen at $-20{ }^{\circ} \mathrm{C}$ until used. The stock solution of ITU was kept in the dark to prevent photodecomposition. The maximum concentration of DMSO applied to the preparations $(0.02 \% \mathrm{vol} / \mathrm{vol})$ was devoid of effect on EPPs.

\subsection{Analysis of the data}

The data are expressed as mean \pm SEM from $n$ experiments. To allow comparisons between different experiments, the EPP amplitude, as well as the MEPP frequency or amplitude and the quantum content, were normalized, with $100 \%$ determined as the averaged values obtained during 10 minutes immediately before applying the test drug. The significance of the differences between means was evaluated by Student $t$ test, when only 2 means were compared, or by 1-way analysis of variance (ANOVA) followed by the Tukey's test whenever multiple comparisons were made. Values of $p<0.05$ were considered to represent statistically significant differences.

\section{Results}

\subsection{Relative role of adenosine $A_{1}$ and $A_{2 A}$ receptors upon aging}

To evaluate the relative importance of adenosine $A_{1}$ receptors vis-a-vis adenosine $A_{2 A}$ receptors, we decided to explore first the action of the stable analogue, CADO, which is not a substrate for adenosine deaminase (e.g., Daly, 1982), and has a low affinity for the adenosine uptake system (Jarvis et al., 1989). In innervated diaphragms from infant rats, and in accordance with what has been previously reported (Pousinha et al., 2010), CADO (30 nM) increased EPP amplitude, but as illustrated in Fig. 1, the magnitude of this excitatory effect decreased with age, turning into an inhibitory effect in aged rats. The effect caused by CADO $(30 \mathrm{nM})$ on the average amplitude of EPPs in all groups studied (\% change: $31 \pm 4.7 \%, n=5$, infant rats, Fig. 1A, E; $21 \pm 7.6 \%, n=5$, young adult rats, Fig. 1B, E; $13 \pm$ $5.7 \%, n=5$, older rats, Fig. $1 \mathrm{C}, \mathrm{E} ;-12 \pm 4.3 \%, n=3$, aged rats, Fig. 1D, E) was statistically significant $(p<0.05$ when compared with absence of CADO (precontrol) in the same experiments, Student $t$ test, Fig. 1E). The effect in innervated diaphragms from older adults or aged rats was also significantly different from that in infant rats $(p<0.05$; ANOVA 1-way analysis of variance followed by Tukey's multiple comparisons test). Interestingly, when CADO (30 $n M)$ was applied in the presence of the selective $A_{2 A}$ receptor antagonist, ZM 241385 (50 nM, Poucher et al., 1995), it caused inhibition of EPP amplitude (Fig. 1A-D), which was more evident in innervated diaphragms from older adult $(-12 \pm 2.4 \%, n=3$; Fig. 1C) or aged rats $(-24 \pm$ $10.2 \%, n=3$; Fig. 1D). On the other hand, in aged rats, the effect of CADO $(30 \mathrm{nM})$ in the absence or presence of the $\mathrm{A}_{2 \mathrm{~A}}$ receptor antagonist, $\mathrm{ZM} 241385(50 \mathrm{nM})$, was not significantly different $(p<0.05$; Student $t$ test). Taken together, these results suggest that until midlife there is a predominant activation of $\mathrm{A}_{2 \mathrm{~A}}$ receptors, which is lost upon aging. Accordingly, and as shown in Fig. 2, when a selective $\mathrm{A}_{1}$ receptor agonist, CPA $(100 \mathrm{nM}$, Williams et al., 1986), was applied after the full excitatory effect of an $A_{2 A}$ selective agonist, CGS 21680 (10 nM, Jarvis et al., 1989), the $A_{1}$ receptor agonist could not revert the excitatory influence of the selective $A_{2 A}$ receptor agonist. On the contrary, when CGS $21680(10 \mathrm{nM})$, the selective $\mathrm{A}_{2 \mathrm{~A}}$ receptor agonist, was applied after the full inhibitory effect of CPA $(100 \mathrm{nM})$, neuromuscular transmission was increased, so that EPP amplitude nearly reverted toward precontrol levels (Fig. 2B). Thus, activation of $\mathrm{A}_{2 \mathrm{~A}}$ receptors was able to counteract the inhibition caused by activation of $A_{1}$ receptors, whereas $A_{1}$ receptor activation was not able to revert the $A_{2 \mathrm{~A}}$ receptor-mediated excitatory action, further supporting the idea that in young animals the excitatory influence predominates over the inhibitory one.

To exclude the hypothesis that in aged rats the $A_{2 A}$ receptors are occupied by endogenous adenosine hampering its activation by an exogenous ligand, we evaluated the effect of CADO (30 nM) after removing endogenous adenosine with ADA ( $2 \mathrm{U} / \mathrm{mL})$, an enzyme that converts adenosine into inosine (see Arch and Newsholme, 1978). By itself, ADA (2 U/mL) was devoid of effect on neuromuscular transmission (data not shown), suggesting that in these experimental conditions the level of extracellular adenosine is probably low. Furthermore, in the presence of ADA (2 $\mathrm{U} / \mathrm{mL})$, the effect of CADO $(30 \mathrm{nM})$ on neuromuscular transmission in aged rats (Fig. 1D) was not significantly different ( $p>0.05, n=3$, Student $t$ test) from what was observed when applied alone.

We previously reported (Pousinha et al., 2010) that the excitatory actions of adenosine at the neuromuscular junction of infant rats require tonic activation of adenosine $A_{1}$ receptors. Thus, we investigated if the excitatory effect of CADO (30 nM) observed in young adult and older adult rats was also prevented by the $\mathrm{A}_{1}$ receptor antagonist, DPCPX $(10 \mathrm{nM})$. This antagonist was used at a concentration only 20 times higher than its $\mathrm{Ki}$ value for $\mathrm{A}_{1}$ receptors in the same preparation (Sebastião et al., 1990) and well below its $\mathrm{Ki}$ value for $\mathrm{A}_{2 \mathrm{~A}}$ receptors (see Jacobson et al., 1992), but as illustrated in Fig. 3, it fully prevented the facilitatory action of CADO (30 nM) in young adult rats (Fig. 3A) and older adult rats (Fig. 3B) $(p<0.05, n=3$, Student $t$ test).

Fig. 4 summarizes the results from experiments where MEPPs and EPPs were recorded simultaneously, to evaluate changes in the quantal content of EPPs. Accordingly to what was previously described for infant rats (Pousinha et al., 2010), CADO $(30 \mathrm{nM})$ induced an increase in the frequency of MEPPs in young adult and older adult rats (Fig. 4A). This effect on the frequency of MEPPs was not accompanied by changes in its mean amplitude (Fig. 4B), indicating that the excitatory effect of CADO $(30 \mathrm{nM})$ is presynaptic, enhancing the release of the transmitter. Indeed, the quantal content of EPPs was significantly increased ( $p<0.05, n=5$, Student $t$ test) by CADO ( $30 \mathrm{nM})$ in infant, young adult, and older adult 
A

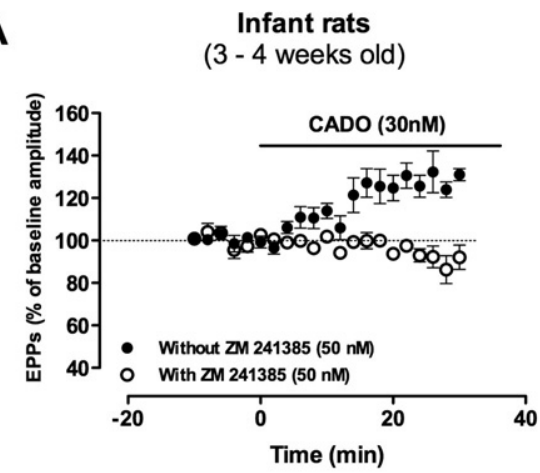

C

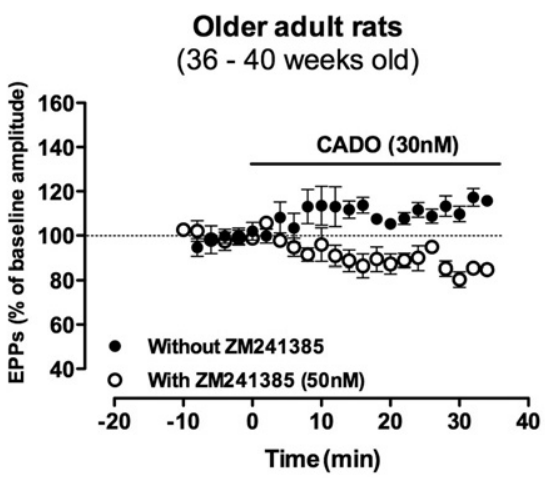

E

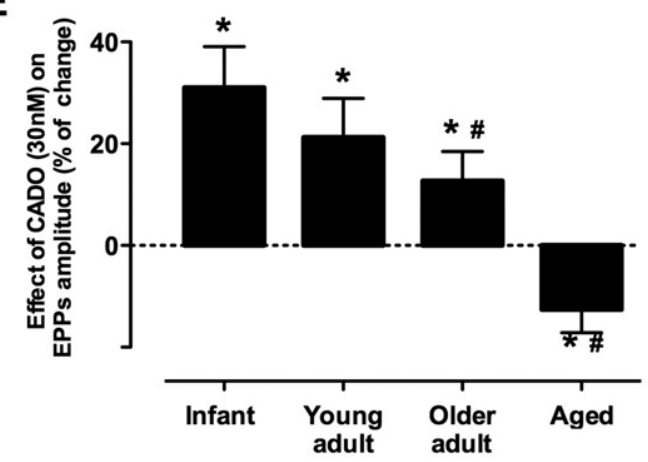

B

Young adult rats

(12 - 16 weeks old)

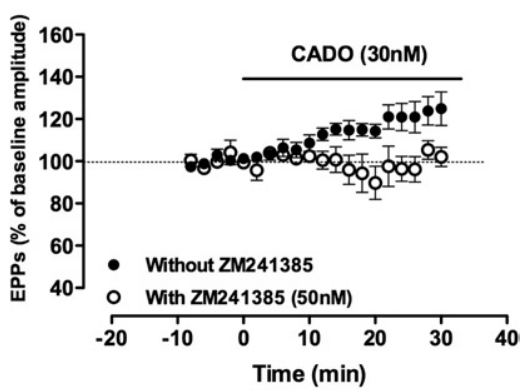

D

Aged rats

(70 - 80 weeks old)

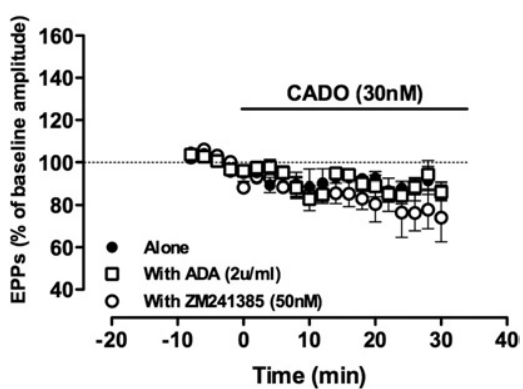

$\mathbf{F}$

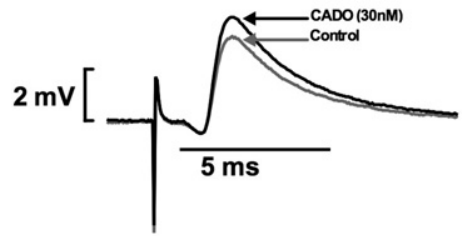

Fig. 1. At submicromolar concentrations, 2-chloroadenosine (CADO) enhances the amplitude of evoked end plate potentials (EPPs) in infant, young adult, and older adult, but not in aged rats. (A-D) The averaged changes in the amplitude of EPPs caused by the stable $\mathrm{A}_{1} / \mathrm{A}_{2 \mathrm{~A}}$ receptor agonist CADO (30 nM) in the absence $(\bullet)$ or in the presence (o) of the selective antagonist of adenosine $\mathrm{A}_{2 \mathrm{~A}}$ receptors, ZM 241385 (50 nM), in infant (A), young adult (B), older adult (C), or aged (D) rats. (D) In aged rats, the effect of CADO is not affected by the presence of adenosine deaminase (ADA; 2 U/mL, $\square$ ), which was used to remove any putative occupation of receptors with the endogenous ligand, adenosine. The adenosine receptor antagonist was added to the preparations at least 45 minutes before addition of the agonist; ADA was added at least 30 minutes before the agonist. The horizontal bars in (A-D) indicate the period of agonist perfusion. Each point, in (A-D) represents the averaged amplitude of 60 successive EPPs; in the ordinates, $100 \%$ represents the averaged EPP amplitude recorded for 10 minutes immediately before addition of CADO $(30 \mathrm{nM}$ ): $2.4 \pm 0.6 \mathrm{mV}, n=8$ (infant rats); $3.0 \pm 0.5 \mathrm{mV}, n=8$ (young adult rats); $2.9 \pm 1.0 \mathrm{mV}, n=8$ (older adult rats); $1.5 \pm 0.3 \mathrm{mV}, n=10$ (aged rats). (E) Bar chart that summarizes the effect of CADO (30 nM) on the amplitude of EPPs in all groups studied; * $p<0.05$ (Student $t$ test), as compared with $0 \%$ (EPP amplitude before CADO in the same experiment); ${ }^{*} p<0.05$ (1-way ANOVA followed by Tukey's multiple comparisons test) as compared with the effect of CADO in infant rats. (F) Representative traces of averaged EPPs recorded from 1 end plate (young adult rat), immediately before (control) and 30 minutes after addition of CADO (30 nM). Resting membrane potential in all experiments at time 0 (i.e., before adding the test drug) ranged from -61 to $-76 \mathrm{mV}$. Perfusion solutions contained $19 \mathrm{mM} \mathrm{Mg}^{2+}$ which prevented muscle action potentials and twitches in response to nerve stimulation.

rats (Fig. 4C). In aged rats, CADO $(30 \mathrm{nM})$ induced the opposite effect, causing a decrease in the frequency of MEPPs (Fig. 4A) without affecting their mean amplitude, indicating that in this group of animals, the inhibitory action of CADO $(30 \mathrm{nM})$ is still exerted at the presynaptic level.

\subsection{Age-dependent changes in balanced $A_{1} / A_{2 A}$ receptor activation by endogenously released adenosine}

Because both $A_{1}$ and $A_{2 A}$ receptors are present at the motor nerve endings, therefore being prone to be activated 

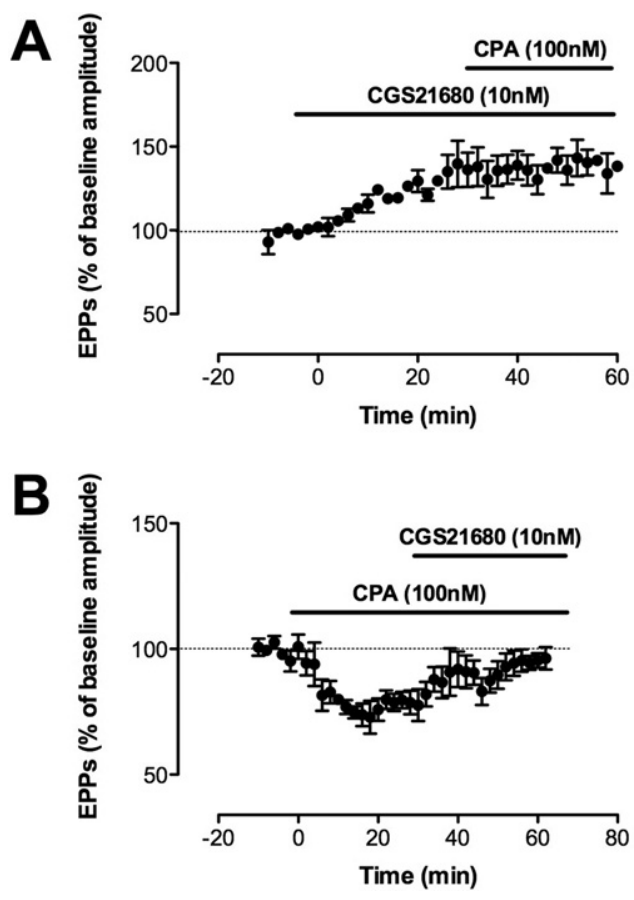

Fig. 2. The $A_{2 A}$ receptor-mediated facilitatory action upon neuromuscular transmission is not reverted by coapplication of an $\mathrm{A}_{1}$ receptor-mediated agonist. Averaged time course changes in the amplitude of evoked end plate potentials (EPPs) caused by (A) 6-cyclopentyladenosine (CPA) $(100$ $\mathrm{nM}$ ) in the presence of the selective $\mathrm{A}_{2 \mathrm{~A}}$ receptor agonist, CGS21680 (10 $\mathrm{nM})$ and by (B) CGS21680 (10 nM) in the presence of the selective $A_{1}$ receptor agonist, CPA $(100 \mathrm{nM})$ in young adult rat end plates, as shown. The horizontal bars indicate the periods of drug perfusion. Each point represents the averaged amplitude of 60 successive EPPs; in the ordinates, $100 \%$ represents the averaged EPP amplitude recorded for 10 minute immediately before addition of each selective agonist in (A), $2.8 \pm 0.4$ $\mathrm{mV}, n=3$; and (B), $2.6 \pm 0.8 \mathrm{mV}, n=3$. Resting membrane potential in all experiments at time 0 (i.e., before adding the test drug) ranged from -61 to $-72 \mathrm{mV}$. Perfusion solutions contained $19 \mathrm{mM} \mathrm{Mg}^{2+}$ which prevented muscle action potentials and twitches in response to nerve stimulation.

by the endogenous ligand, the next series of experiments was designed to assess if the $A_{1} / A_{2 A}$ activation balance could be influenced by age. To do so, extracellular levels of adenosine were increased by using the adenosine kinase inhibitor, ITU $(10 \mu \mathrm{M})$. We previously showed (Pousinha et al., 2010) that ITU $(10 \mu \mathrm{M})$ enhanced the neuromuscular transmission of infant rats, while being virtually devoid of effect on the resting membrane potential of the muscle fiber, an effect attributed to activation of $\mathrm{A}_{2 \mathrm{~A}}$ receptors by released adenosine. We therefore evaluated if this excitatory effect was maintained upon aging. Fig. 5 illustrates the effect of ITU $(10 \mu \mathrm{M})$ on the amplitude of EPPs in all groups studied. As shown, ITU $(10 \mu \mathrm{M})$ increased $(p<$ $0.05, n=5$, Student $t$ test) the mean amplitude of EPPs in infant (Fig. 5A, E), young adult (Fig. 5B, E), and older adult (Fig. 5C, E) rats. However, in aged rats, ITU $(10 \mu \mathrm{M})$ inhibited neuromuscular transmission, decreasing $(p<$ 0.05, $n=4$ ) the mean amplitude of EPPs (Fig. 5D, E).
Comparison among the different groups (ANOVA 1-way analysis of variance followed by Tukey's multiple comparisons test) confirmed that the effect of ITU $(10 \mu \mathrm{M})$ in aged rats was significantly different ( $p<0.05, n=4$, Student $t$ test) from that in infant rats. As expected, when ITU (10 $\mu \mathrm{M})$ was perfused in the presence of the $A_{2 A}$ receptor selective antagonist, ZM241385, the excitatory effect was no longer evident (Fig. 5). Interestingly, in older adult rats the excitatory effect of ITU $(10 \mu \mathrm{M})$ turned into an inhibitory one $(-29 \pm 10.8 \%, n=4$, Fig. $5 \mathrm{C} ; p<0.05$, Student $t$ test), indicating that at this age group both $\mathrm{A}_{1}$ and $\mathrm{A}_{2 \mathrm{~A}}$ receptors can be hit by endogenously released adenosine.
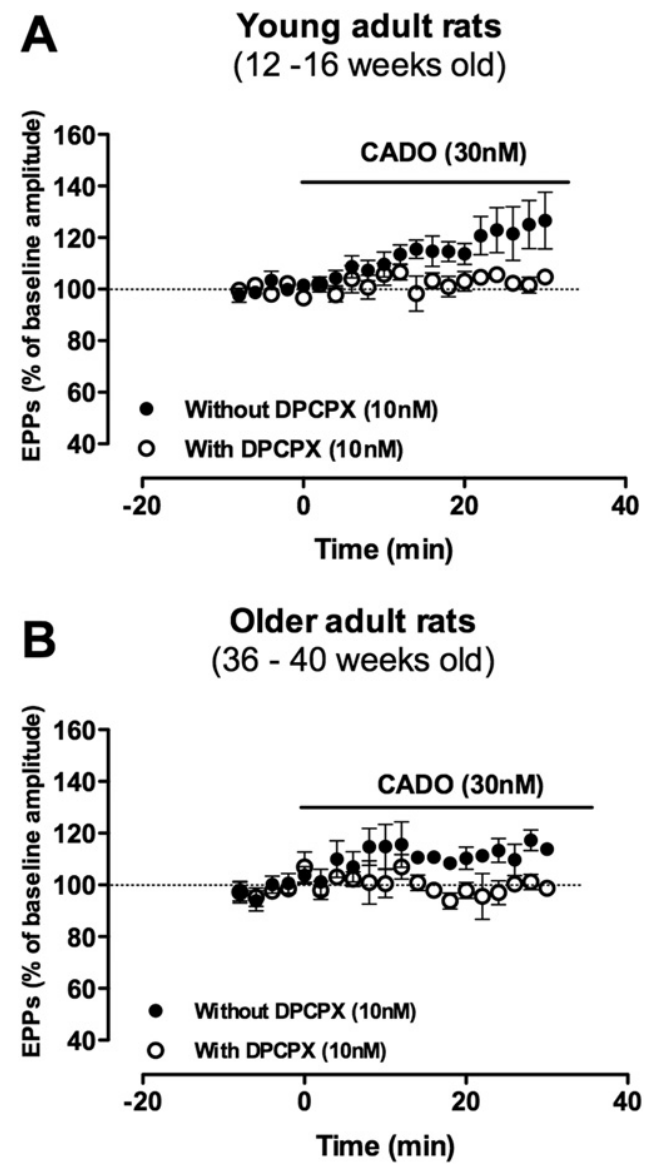

Fig. 3. The facilitatory effect of 2-chloroadenosine (CADO) $(30 \mathrm{nM})$ is prevented by the selective $A_{1}$ receptor antagonist. Averaged time course changes in the amplitude of evoked end plate potentials (EPPs) caused by CADO (30 nM) in the absence $(\bullet)$ or in the presence (o) of the selective $\mathrm{A}_{1}$ receptor antagonist, DPCPX $(10 \mathrm{nM})$, in young adult (A) and older adult (B) rat end plates as shown. The adenosine receptor antagonist was added to the preparations at least 45 minutes before addition of the agonist. The horizontal bars indicate the period of agonist perfusion. Each point represents the averaged amplitude of 60 successive EPPs; in the ordinates, $100 \%$ represents the averaged EPP amplitude recorded for 10 minutes immediately before addition of $30 \mathrm{nM} \mathrm{CADO} \mathrm{(A),} 3.1 \pm 0.5 \mathrm{mV}, n=8$; and (B) $2.5 \pm 0.6 \mathrm{mV}, n=8$. Resting membrane potential in all experiments at time 0 (i.e., before adding the test drug) ranged from -62 to $-73 \mathrm{mV}$. Perfusion solutions contained $19 \mathrm{mM} \mathrm{Mg}^{2+}$ which prevented muscle action potentials and twitches in response to nerve stimulation. 

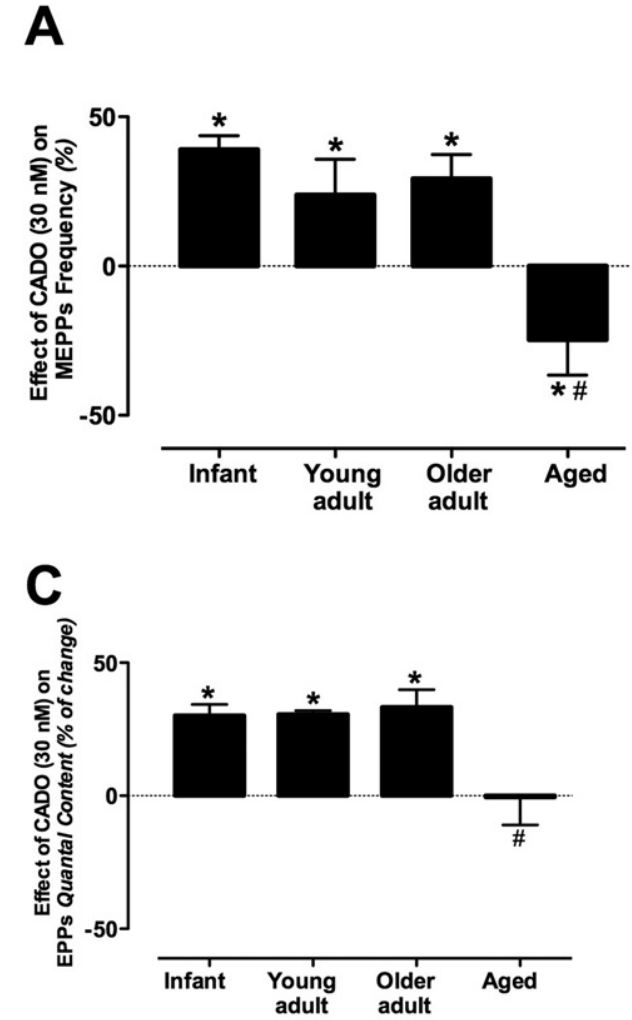

B

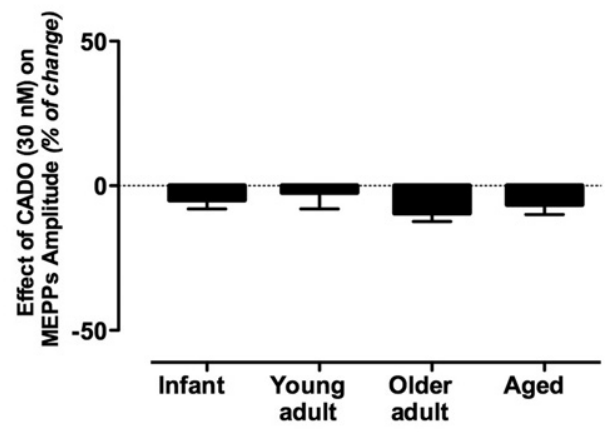

D

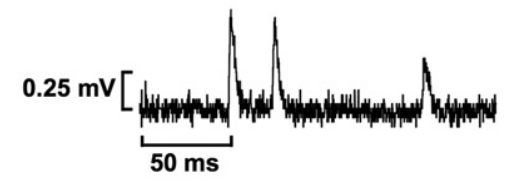

Fig. 4. At submicromolar concentrations, 2-chloroadenosine (CADO) enhances both the frequency of miniature end plate potentials (MEPPs) and the quantal content of end plate potentials (EPPs) in infant, young adult, and older adult rats, but not in aged rats. (A-C) The effect of CADO (30 nM) on the averaged frequency (A) and amplitude (B) of MEPPs, as well as quantal content (C) of EPPs in infant, young adult, older adult, and aged rats. In the ordinates, 0\% represents the averaged number of events per 100 seconds (A), averaged amplitude recorded for 100 consecutive MEPPs (B), and the quantal content calculated immediately before addition of CADO $(30 \mathrm{nM})$. The effect induced by CADO $(30 \mathrm{nM})$ on the frequency of MEPPs and on the quantal content of EPPs in infant, young adult, and older adult rats was significantly different from the control. $* p<0.05$ (Student $t$ test) as compared with $0 \%$ (control waves before CADO); ${ }^{\#} p<0.05$ (1-way analysis of variance [ANOVA] followed by Tukey's multiple comparisons test) as compared with the effect of CADO in infant rats. (D) Representative sample of MEPPs recordings. Perfusion solutions contained $19 \mathrm{mM} \mathrm{Mg}^{2+}$.

This inhibitory effect can be related to $\mathrm{A}_{1}$ receptor activation by released adenosine, because, as expected, it was prevented by the adenosine $A_{1}$ receptor selective antagonist, DPCPX (10 nM, $n=3)$.

Accordingly to what was observed with CADO $(30 \mathrm{nM})$, ITU $(10 \mu \mathrm{M})$ induced an increase in the frequency of MEPPs in infant, young adult, and older adult rats (Fig. 5G). This effect was not accompanied by changes in the mean amplitude of MEPPs (Fig. 5F) and therefore, ITU $(10 \mu \mathrm{M})$ significantly ( $p<0.05, n=4-5$, Student $t$ test) increased the quantal content of EPPs (Fig. 5H) in those age groups. Interestingly, in aged animals, ITU $(10 \mu \mathrm{M})$ decreased the frequency of MEPPs $(-20 \pm 6.3 \%, n=3$; Fig. 5G) without affecting its mean amplitude (Fig. 5F), decreasing the quantal content of EPPs (Fig. 5H); these inhibitory actions were prevented by the selective A1 receptor antagonist DPCPX $(10 \mathrm{nM})$. One may therefore conclude that under situations of enhanced release of endogenous adenosine, due to inhibition of adenosine kinase, adenosine-mediated modulation of neuromuscular transmission also shifts from excitatory to inhibitory upon aging.

\subsection{Age-dependent influence of inhibitory receptors}

To evaluate if the inhibitory action of adenosine on neuromuscular transmission was affected by aging, we studied the effect of the selective adenosine $\mathrm{A}_{1}$ receptor agonist, CPA, upon aging (Fig. 6). As expected, CPA (100 nM) decreased the mean amplitude of EPPs in all groups studied $(p<0.05$, when compared with absence of CPA [precontrol] in the same experiments, $n=4-5$, Student $t$ test). Among groups, there were no statistically significant differences $(p>0.05 ; 1$-way ANOVA followed by Tukey's multiple comparisons test). This monotonous effect of CPA $(100 \mathrm{nM})$ suggests that the inhibitory role of adenosine $\mathrm{A}_{1}$ receptors on neuromuscular transmission is maintained upon aging.

\subsection{Age-dependent influence of facilitatory receptors}

As illustrated in Fig. 7, the selective $\mathrm{A}_{2 \mathrm{~A}}$ receptor agonist, CGS $21680(10 \mathrm{nM})$, increased $(p<0.05, n=4-5$, Student $t$ test) the amplitude of EPPs in infant (Fig. 7A, E), young adult (Fig. 7B, E), and older adult (Fig. 7C, E) rats. 
A

Infant rats

(3- 4 weeks old)

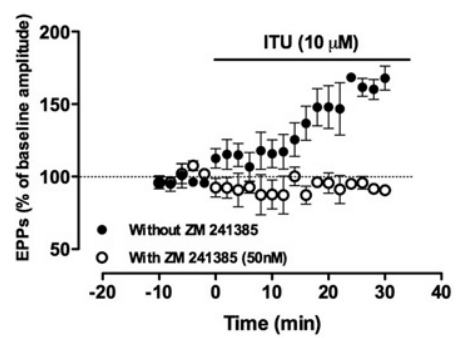

C

Older adult rats

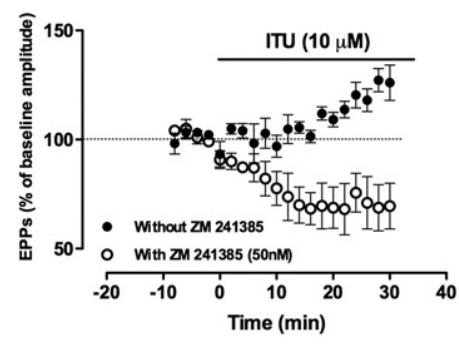

$\mathbf{E}$

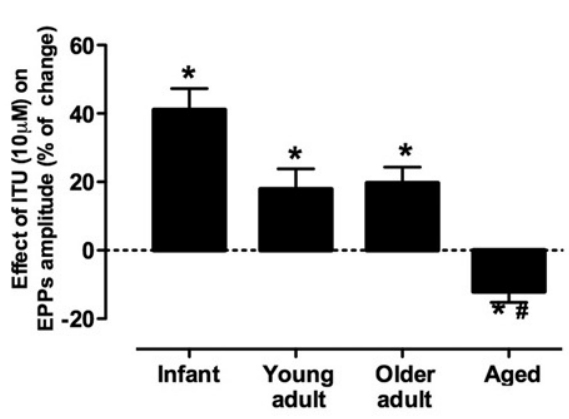

G

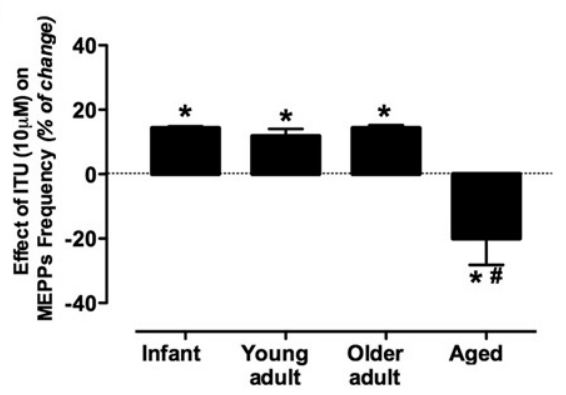

B

Young adult rats

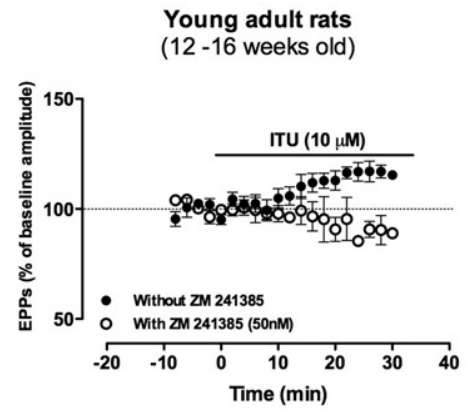

Aged rats

D

(70 - 80 weeks old)

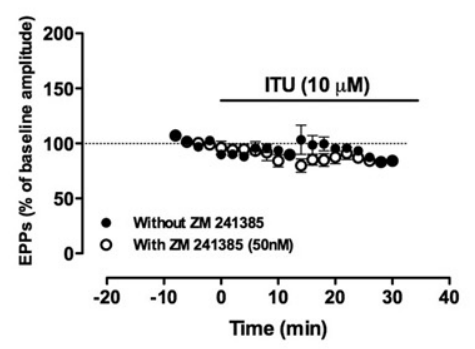

$\mathbf{F}$

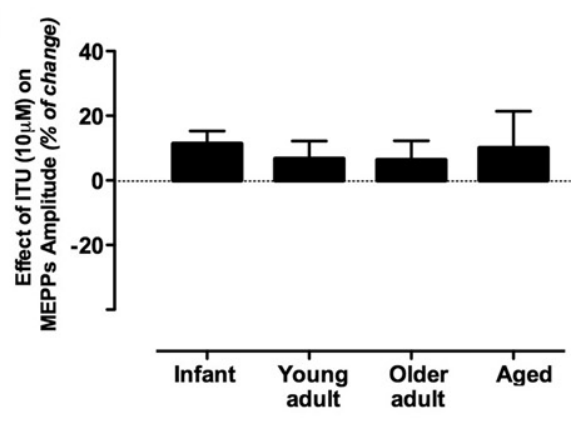

H

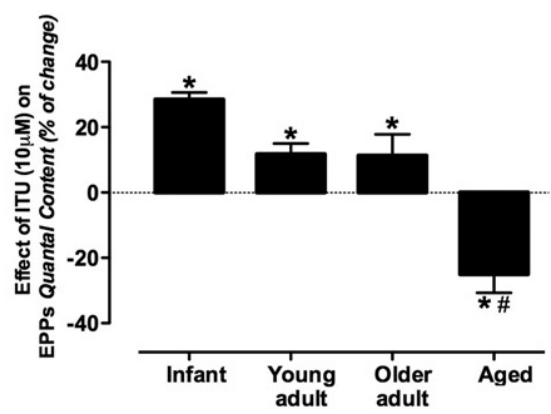

Fig. 5. The adenosine kinase inhibitor, iodotubericidin (ITU), enhances the amplitude of evoked end plate potentials (EPPs), the frequency of miniature end plate potentials (MEPPs) and the quantal content of EPPs in infant, young adult, and older adult rats, but not in aged rats. (A-D) Averaged changes in the amplitude of EPPs caused by ITU $(10 \mu \mathrm{M})$ in the absence $(\bullet)$ or in the presence (o) of the selective antagonist of adenosine $\mathrm{A}_{2 \mathrm{~A}}$ receptors, ZM 241385 (50 $\mathrm{nM}$ ), in infant (A), young adult (B), older adult (C), or aged (D) rats The adenosine receptor antagonist was added to the preparations at least 45 minutes before addition of ITU. The horizontal bars represent the period of ITU perfusion; each point represents the averaged amplitude of 60 successive EPPs; in the ordinates, $100 \%$ represents the averaged EPP amplitude recorded for 10 minutes immediately before addition of ITU $(10 \mu \mathrm{M}): 3.2 \pm 0.5 \mathrm{mV}, n=8$ (infant rats); $2.0 \pm 0.4 \mathrm{mV}, n=8$ (young adult rats); $1.6 \pm 0.4 \mathrm{mV}, n=8$ (older adult rats); $1.8 \pm 0.3 \mathrm{mV}, n=7$ (aged rats). (E-H) Bar chart that summarizes the effect of ITU $(10 \mu \mathrm{M})$ on the average amplitude of EPPs (E), on the average amplitude (F) and frequency (G) of MEPPs, as well as quantal content (G) of EPPs in all groups studied. In the ordinates 0\% represents the averaged EPP amplitude recorded for 10 minutes immediately before addition of ITU (10 $\mu \mathrm{M})(\mathrm{E})$, averaged amplitude recorded for 100 consecutive MEPPs (F), averaged number of events per 100 sec $(\mathrm{G})$, and the quantal content calculated immediately before addition of ITU $(10 \mu \mathrm{M})$. The effect induced by ITU $(10 \mu \mathrm{M})$ on the averaged amplitude of EPPs, frequency of MEPPs, and on the quantal content of EPPs in infant, young adult, and older adult rats was significantly different from the control. * $p<0.05$ (Student $t$ test) as compared with $0 \%$ (control waves before ITU); ${ }^{\#} p<0.05$ (1-way analysis of variance [ANOVA] followed by Tukey's multiple comparisons test) as compared with the effect of ITU in infant rats. Resting membrane potential in all experiments at time 0 (i.e., before adding the test drug) ranged from -60 to $-77 \mathrm{mV}$. Perfusion solutions contained $19 \mathrm{mM} \mathrm{Mg}^{2+}$ which prevented muscle action potentials and twitches in response to nerve stimulation. 
A

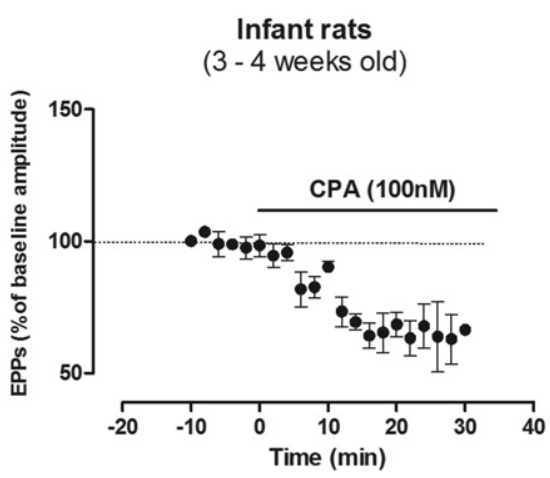

C

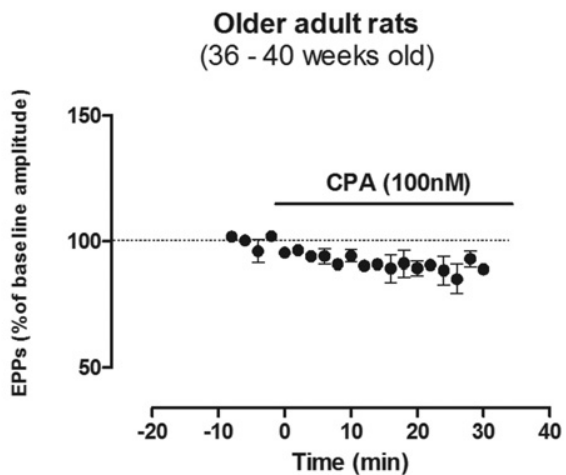

B
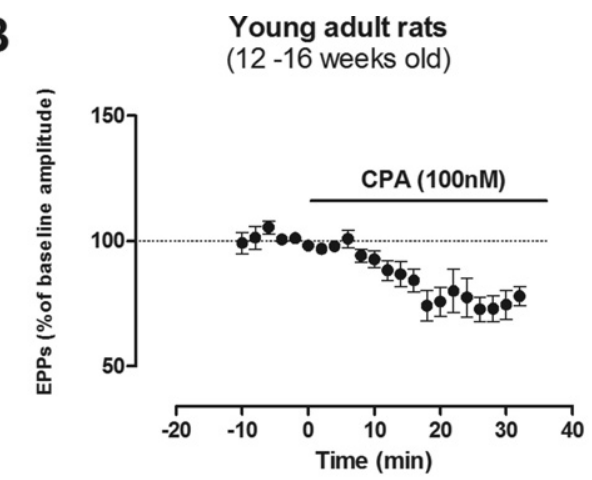

D

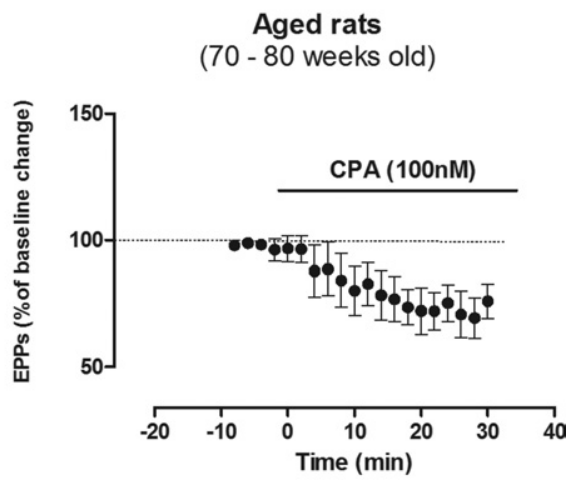

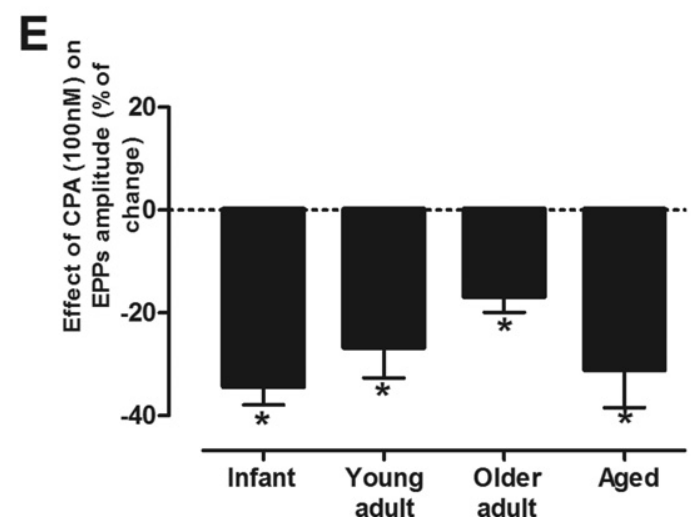

Fig. 6. $A_{1}$ receptor activation decreases the average amplitude of evoked end plate potentials (EPPs) in all groups studied. (A-D) Averaged changes in the amplitude of EPPs caused by the $\mathrm{A}_{1}$ receptor agonist 6-cyclopentyladenosine (CPA) (100 nM) in infant (A), young adult (B), older adult (C), or aged (D) rats; the horizontal bars indicate the period of drugs perfusion; each point represents the averaged amplitude of 60 successive EPPs; in the ordinates, $100 \%$ represents the averaged EPP amplitude recorded for 10 minutes immediately before addition of CPA (100 nM, $1.6 \pm 0.3 \mathrm{mV}, n=5 \mathrm{infant}$ rats; $1.4 \pm 0.3$ $\mathrm{mV}, n=5$ young adult rats; $3.4 \pm 0.5 \mathrm{mV}, n=4$ older adult rats; $2.4 \pm 1.2 \mathrm{mV}, n=4$ aged rats. (E) Bar chart that summarizes the effect of CPA (100 $\mathrm{nM}$ ) on the amplitude of EPPs in all groups studied; * $p<0.05$ (Student $t$ test), as compared with 0\% (EPP amplitude before CPA [100 nM]) in the same experiment; ${ }^{*} p<0.05$ (1-way analysis of variance [ANOVA] followed by Tukey's multiple comparisons test) as compared with the effect of CPA (100 $\mathrm{nM}$ ) in infant rats. Resting membrane potential in all experiments at time 0 (i.e., before adding the test drug) ranged from -60 to $-70 \mathrm{mV}$. Perfusion solutions contained $19 \mathrm{mM} \mathrm{Mg}^{2+}$ which prevented muscle action potentials and twitches in response to nerve stimulation.

Unexpectedly, in aged rats (Fig. 7D, E) CGS $21680(10 \mathrm{nM})$ failed $(p>0.05, n=4)$ to enhance neuromuscular transmission suggesting the absence of functional adenosine $\mathrm{A}_{2 \mathrm{~A}}$ receptors in that age. The absence of an excitatory effect in aged rats could be related to full occupancy of the receptors by endogenously released adenosine. To exclude this hypothesis we tested the effect of CGS 21680 $(10 \mathrm{nM})$ in the presence of ADA $(2 \mathrm{U} / \mathrm{mL})$. By itself,
ADA $(2 \mathrm{U} / \mathrm{mL})$ did not significantly modify the amplitude of EPPs $(-12 \pm 4.6 \mathrm{mV}, n=3)$, indicating that the level of extracellular adenosine was low. When CGS $21680(10 \mathrm{nM})$ was applied 30 minutes after ADA (2 $\mathrm{U} / \mathrm{mL}$ ) addition, the mean amplitude of EPPs remained unchanged $(-5 \pm 0.8 \%, n=3)$, suggesting that the absence of the excitatory effect is not related to maximum receptor occupancy by the endogenous ligand. 
A

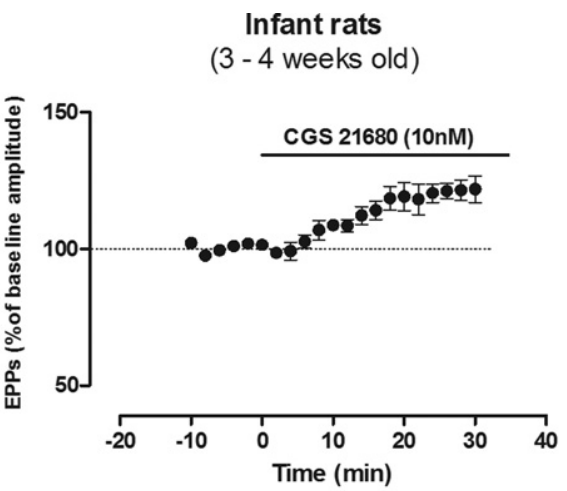

C

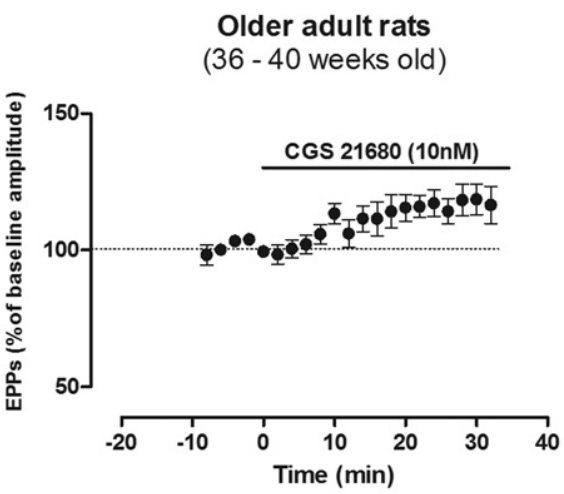

B

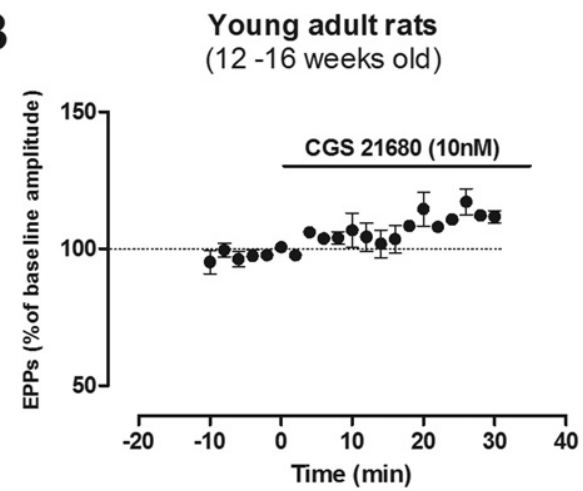

D

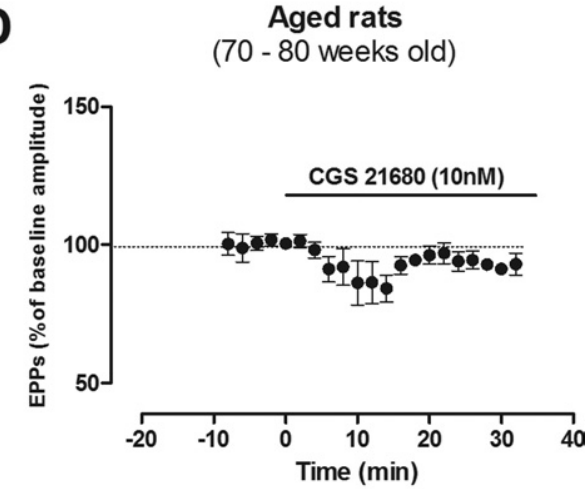

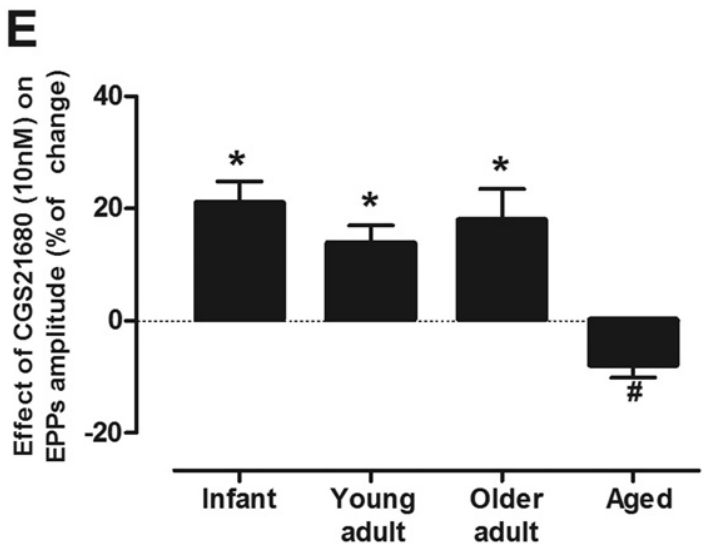

Fig. 7. The selective $A_{2 A}$ receptor agonist, CGS21680, increases the average amplitude of evoked end plate potentials (EPPs) in infant, young adult, and older adult rats, but not in aged rats. (A-D) Averaged changes in the amplitude of EPPs caused by the $\mathrm{A}_{2 \mathrm{~A}}$ receptor agonist CGS21680 (10 nM) in infant (A), young adult (B), older adult (C), or aged (D) rats; the horizontal bar represents the period of agonist perfusion; each point represents the averaged amplitude of 60 successive EPPs; in the ordinates, 100\% represents the averaged EPP amplitude recorded for 10 minutes immediately before starting CGS21680 (10 nM) perfusion, which was $2.6 \pm 0.6 \mathrm{mV}, n=5$ infant rats; $2.0 \pm 0.5 \mathrm{mV}, n=5$ young adult rats; $2.6 \pm 0.4 \mathrm{mV}, n=4$ older adult rats; $1.5 \pm 0.3 \mathrm{mV}, n=$ 4 aged rats. (E) Bar chart that summarizes the effect of CGS21680 (10 nM) on the amplitude of EPPs in all groups studied; * $p<0.05$ (Student $t$ test), as compared with $0 \%$ (EPP amplitude before 6-cyclopentyladenosine [CPA] $100 \mathrm{nM}$ ) in the same experiment; ${ }^{*} p<0.05$ (1-way analysis of variance [ANOVA] followed by Tukey's multiple comparisons test) as compared with the effect of CPA (100 nM) in infant rats. Resting membrane potential in all experiments at time 0 (i.e., before adding the test drug) ranged from -63 to $-74 \mathrm{mV}$. Perfusion solutions contained $19 \mathrm{mM} \mathrm{Mg}^{2+}$ which prevented muscle action potentials and twitches in response to nerve stimulation.

\section{Discussion}

The main finding in the present work was that age influences adenosine $A_{1}$ and $A_{2 A}$ receptors at the rat diaphragm neuromuscular junction, in a different manner. The magnitude of the excitatory effects on neuromuscular transmission caused by endogenously-released adenosine or by a mixed
$\mathrm{A}_{1} / \mathrm{A}_{2 \mathrm{~A}}$ receptor agonist tends to decrease upon aging, disappearing in aged rats, where only $\mathrm{A}_{1}$ receptor-mediated inhibition was evident. Considering independent activation of $A_{1}$ or $A_{2 A}$ receptors by selective ligands, the magnitude of the $A_{1}$ receptor-mediated inhibition is kept about constant throughout age; in contrast, the magnitude of $\mathrm{A}_{2 \mathrm{~A}}$ 
receptor-mediated facilitation is about the same up to middle-aged (older adult rats), but is absent at the neuromuscular junction of aged rats. Therefore, it appears that upon aging there is a gradual tendency for preponderance of inhibition, over excitation, when both receptors are simultaneously activated, despite proper $A_{1}$ and $A_{2 A}$ receptor functioning up to middle age.

Neuromuscular junctions differ in quantal content, safety factor, and adaptation to repetitive activation (see Ermilov et al., 2007; Rowley et al., 2007). Whether such differences might influence the presently reported effects of adenosine upon aging, needs to be explored at the light of the results obtained by Rowley et al. (2007) and Ermilov et al. (2007). However, in a previous work (see Ginsborg and Hirst, 1972) the initial quantal content of EPPs (either being low, in experiments where muscle contractions were paralyzed by high magnesium, or high in the experiments where muscle contractions were paralyzed by tubocurarine) did not influence the inhibitory effects of adenosine at the rat diaphragm neuromuscular junction. How adenosine influences safety factor variability in nerve terminals innervating different fiber types (see Ermilov et al., 2007) cannot be answered in the present work and awaits further investigation.

It is well established that adenosine kinase inhibitors, such as ITU, increase extracellular adenosine availability. In the present work, the excitatory effect of low concentrations of CADO and ITU, observed in infant rats (Pousinha et al., 2010), tended to decrease upon aging, even disappearing in aged rats (70-80 weeks old). The enhancement of neuromuscular transmission caused by the adenosine kinase inhibitor, ITU, as well as that caused by the mixed $A_{1} / A_{2 A}$ receptor agonist, $\mathrm{CADO}$, should be attributed to adenosine $\mathrm{A}_{2 \mathrm{~A}}$ receptor activation because they were antagonized by preincubation with the selective $\mathrm{A}_{2 \mathrm{~A}}$ receptor antagonist $\mathrm{ZM} 241385 . \mathrm{A}_{2 \mathrm{~A}}$ receptor blockade transformed the excitatory effects of those drugs into inhibitory ones. This suggests that the influence of ITU and CADO upon neuromuscular transmission results from a balance between activation of adenosine excitatory $A_{2 A}$ and inhibitory $A_{1}$ receptors. The facilitation of neuromuscular transmission caused by ITU or CADO should be attributed to a presynaptic action, i.e., to an increase in the release of acetylcholine from the phrenic nerve endings, because these drugs increased the quantal content of end plate potentials without affecting the average amplitude of MEPPs recorded concomitantly.

The failure of nanomolar concentrations of CADO and ITU to increase neuromuscular transmission in aged rats, suggests that those animals lost the ability to activate $A_{2 A}$ receptors. This hypothesis is supported by (1) the observation that the effect of those drugs was not changed in preparations preincubated with the selective $\mathrm{A}_{2 \mathrm{~A}}$ receptor antagonist, ZM241385, suggesting that only $\mathrm{A}_{1}$ receptors become activated together with the absence of excitatory effect of the $\mathrm{A}_{2 \mathrm{~A}}$ receptor agonist, CGS 21680, when applied to aged rats. (2) Full occupancy of $\mathrm{A}_{2 \mathrm{~A}}$ receptors by high levels of endogenous adenosine cannot account for this lack of effect, because when these drugs were applied in the presence of adenosine deaminase, their effect on neuromuscular transmission was not changed. One possible explanation for the absence of adenosine excitatory effects could be a decrease in the number of $\mathrm{A}_{2 \mathrm{~A}}$ receptors or/and to a decrease in the affinity of the receptor to its ligand. Nerve endings represent only a minor proportion of the tissue content in a nerve-muscle preparation, which precludes the use of receptor quantitative or semiquantitative assays, such as ligand binding studies or Western blot analysis. These approaches have been done in brain tissue, showing that the number of $\mathrm{A}_{2 \mathrm{~A}}$ receptors, their affinity to ligands, and their coupling to $G$ protein, is decreased in striatal membranes of aged rats (24 months) when compared with young adult animals (3 months) (Lopes et al., 1999). Also, the expression of $\mathrm{A}_{2 \mathrm{~A}}$ messenger (m)RNA is decreased in striatum of aged rats (Schiffmann and Vanderhaeghen, 1993) and the excitatory effect of the $\mathrm{A}_{2 \mathrm{~A}}$ receptor agonist, CGS 21680, on the spontaneous outflow of glutamate and aspartate in striatum was lost in aged rats (Corsi et al., 1999). So, in what concerns $\mathrm{A}_{2 \mathrm{~A}}$ receptor-mediated neuromodulation, the neuromuscular junction appears to behave more likely the striatum, in clear contrast with what happens in the hippocampus, where $\mathrm{A}_{2 \mathrm{~A}}$ receptor-mediated excitatory tonus is increased upon aging (Cunha et al., 1995; Lopes et al., 1999). Interestingly, the motor inhibitory adenosinergic tone is increased in aged animals with respect to young animals (Popoli et al., 1998), which can be attributed, at least in part, to a loss of excitatory tonus at the neuromuscular junction (present report) and striatum (Corsi et al., 1999; Lopes et al., 1999; Schiffmann and Vanderhaeghen, 1993).

As observed in infant rats (Pousinha et al., 2010), the $\mathrm{A}_{2 \mathrm{~A}}$ receptor-mediated facilitation of neuromuscular transmission was antagonized, not only by the selective $A_{2 A}$ receptor antagonist, and also, by the $A_{1}$ selective receptor antagonist, suggesting that the interaction between both receptors is maintained upon aging. Two possibilities that are not mutually exclusive can be advanced: (1) the formation of $\mathrm{A}_{2 \mathrm{~A}}$ and $\mathrm{A}_{1}$ receptors heteromers, as it has been shown to occur at glutamatergic nerve terminals (Ciruela et al., 2006) and astrocytes (Cristóvão-Ferreira et al., 2011). In these conditions blockade of the $A_{1}$ receptor molecule could induce a conformational change in the heteromer that does not allow either $\mathrm{A}_{2 \mathrm{~A}}$ agonist binding or effective coupling to the $A_{2 A}$ transducing system. Indeed, heteromerization of $G$ protein coupled receptors may affect several aspects of receptor functioning (see Franco et al., 2008), so that monomers and heteromers can have distinct pharmacological and signaling properties. Therefore, age-dependent changes in the proportion of adenosine receptors in a heteromeric or monomeric form may, at least in part, be responsible for the lost of excitatory effects in aged rats(2). An $A_{1} / A_{2 A}$ receptor crosstalk through intracellular transducing pathways down- 
stream to receptor binding (see Sebastião and Ribeiro, 2000), which would also lead to the need of $A_{1}$ receptor function to trigger an $\mathrm{A}_{2 \mathrm{~A}}$ receptor-mediated response.

Several authors reported morphological and physiological changes that are related to the decline of the neuromuscular system with aging, as for example, loss of motor neurons, altered neurotransmitter release, disruption of postsynaptic acetylcholine receptor organization, denervation and reinnervation of muscle fibers, and motor unit remodeling (see Delbono, 2003). In rat diaphragm, the quantal content was reported to increase during the first 9 months of life and then to decline (Kelly, 1978). The reduction in $\mathrm{A}_{2 \mathrm{~A}}$ receptors effects in aged rats might be one of the causes of the age-related changes in the neuromuscular transmission, because these receptors are known to influence the action of several neurotransmitters/neuromodulators/receptors/transporters at the nerve terminal (see Sebastião and Ribeiro, 2009). For instance, $A_{2 A}$ receptors at motor nerve terminals trigger the action of brain derived neurotrophic factor (BDNF) (Pousinha et al., 2006), which enhances transmitter release at developing end plates (Boulanger and Poo, 1999), improves neuromuscular transmission in the adult rat diaphragm (Mantilla et al., 2004) and facilitates synaptic efficacy by increasing presynaptic depolarization at the neuromuscular junction (see Huang and Reichardt, 2001). BDNF is also important for maintenance of acetylcholine receptor clustering in the end plate (Belluardo et al., 2001; Gonzalez et al., 1999). Therefore, the decrease of $A_{2 A}$ receptors upon aging can compromise BDNF actions that occur at the neuromuscular junction. Interestingly, studies performed on adenosine receptors knockout $(\mathrm{KO})$ mice revealed that $\mathrm{A}_{2 \mathrm{~A}}$ receptors play much more important roles than $A_{1}$ receptors in regulating locomotor activity (Huang et al., 2005), because both $\mathrm{A}_{2 \mathrm{~A}}$ receptor $\mathrm{KO}$ and double $\mathrm{A}_{1}-\mathrm{A}_{2 \mathrm{~A}}$ receptors $\mathrm{KO}$ mice present lower locomotion activity and consume less oxygen than their wild type controls and apparently unaltered in $\mathrm{A}_{1}$ receptor $\mathrm{KO}$ mice. Though those changes are usually regarded as a result of changes in basal ganglia control of motor activity, $\mathrm{A}_{2 \mathrm{~A}}$ receptor changes at the neuromuscular junction may also play a role.

In conclusion, the work here reported clearly documents that aging influences adenosine $\mathrm{A}_{1}$ and $\mathrm{A}_{2 \mathrm{~A}}$ receptors, at the motor nerve terminals, in a different manner. The actions of $\mathrm{A}_{2 \mathrm{~A}}$ receptors decrease with aging, even disappearing in aged rats. It remains to be clarified what are the consequences of the absence of these receptors for fine-tuning of motor control and whether this relates to the age-associated decline in neuromuscular control.

\section{Disclosure statement}

The authors disclose no conflicts of interest.

The animals were handled according to European Community guidelines and Portuguese Law on animal care.

\section{Acknowledgements}

We thank Dr. Luisa V. Lopes for data discussion and Mr. João Baião for animal handling. The animal housing facilities of the Institute of Physiology in the Faculty of Medicine at the University of Lisbon are also acknowledged. This work was supported by Fundação para a Ciência e a Tecnologia (FCT), Portugal and European Union (Grant NEREPLAS, COST B30). P.A.P. is the recipient of a FCT fellowship (Grant SFRH/BD/28073/2006).

\section{References}

Arch, J., Newsholme, E., 1978. The control of metabolism and the hormonal role of adenosine, in: Campbell, P.N., Aldridge, W.N. (Eds.), Essays in Biochemistry, Academic Press, New York, pp. 82-123.

Belluardo, N., Westerblad, H., Mudó, G., Casabona, A., Bruton, J., Caniglia, G., Pastoris, O., Grassi, F., Ibáñez, C.F., 2001. Neuromuscular junction disassembly and muscle fatigue in mice lacking neurotrophin-4. Mol. Cell. Neurosci. 18, 56-67.

Boulanger, L.M., Poo, M.M., 1999. Presynaptic depolarization facilitates neurotrophin-induced synaptic potentiation. Nat. Neurosci. 2, 346351.

Ciruela, F., Casadó, V., Rodrigues, R.J., Luján, R., Burgueño, J., Canals, M., Borycz, J., Rebola, N., Goldberg, S.R., Mallol, J., Cortés, A., Canela, E.I., López-Giménez, J.F., Milligan, G., Lluis, C., Cunha, R.A., Ferré, S., Franco, R., 2006. Presynaptic control of striatal glutamatergic neurotransmission by adenosine A1-A2A receptor heteromers. J. Neurosci. 26, 2080-2087.

Correia-de-Sá, P., Sebastião, A.M., Ribeiro, J.A., 1991. Inhibitory and excitatory effects of adenosine receptor agonists on evoked transmitter release from phrenic nerve ending of the rat. Br. J. Pharmacol. 103, $1614-1620$.

Corsi, C., Melani, A., Bianchi, L., Pepeu, G., Pedata, F., 1999. Effect of adenosine $\mathrm{A} 2 \mathrm{~A}$ receptor stimulation on GABA release from the striatum of young and aged rats in vivo. Neuroreport 10, 3933-3937.

Cristóvão-Ferreira, S., Navarro, G., Brugarolas, M., Pérez-Capote, K., Vaz, S.H., Fattorini, G., Conti, F., Lluis, C., Ribeiro, J.A., McCormick, P.J., Casadó, V., Franco, R., Sebastião, A.M., 2011. Modulation of GABA transport by adenosine A1R-A2AR heteromers, which are coupled to both Gs- and G(i/o)-proteins. J. Neurosci. 31, 15629-15639.

Cunha, R.A., Constantino, M.C., Sebastião, A.M., Ribeiro, J.A., 1995. Modification of A1 and A2a adenosine receptor binding in aged striatum, hippocampus and cortex of the rat. Neuroreport 6, 1583-1588.

Cunha, R.A., Sebastião, A.M., 1993. Adenosine and adenine nucleotides are independently released from both the nerve terminals and the muscle fibres upon electrical stimulation of the innervated skeletal muscle of the frog. Pflugers Arch. 424, 503-510.

Daly, J.W., 1982. Adenosine receptors: targets for future drugs. J. Med. Chem. 25, 197-207.

Delbono, O., 2003. Neural control of aging skeletal muscle. Aging Cell 2, 21-29.

Diógenes, M.J., Costenla, A.R., Lopes, L.V., Jerónimo-Santos, A., Sousa, V.C., Fontinha, B.M., Ribeiro, J.A., Sebastião, A.M., 2011. Enhancement of LTP in aged rats is dependent on endogenous BDNF. Neuropsychopharmacology 36, 1823-1836.

Ermilov, L.G., Mantilla, C.B., Rowley, K.L., Sieck, G.C., 2007. Safety factor for neuromuscular transmission at type-identified diaphragm fibers. Muscle Nerve 35, 800-803.

Fatt, P., Katz, B., 1951. An analysis of the end-plate potential recorded with an intracellular electrode. J. Physiol. 115, 320-370.

Franco, R., Casadó, V., Cortés, A., Pérez-Capote, K., Mallol, J., Canela, E., Ferré, S., Lluis, C., 2008. Novel pharmacological targets based on receptor heteromers. Brain Res. Rev. 58, 475-482. 
Ginsborg, B.L., Hirst, G.D., 1972. The effect of adenosine on the release of the transmitter from the phrenic nerve of the rat. J. Physiol. 224, 629-645.

Gonzalez, M., Ruggiero, F.P., Chang, Q., Shi, Y.J., Rich, M.M., Kraner, S., Balice-Gordon, R.J., 1999. Disruption of Trkb-mediated signaling induces disassembly of postsynaptic receptor clusters at neuromuscular junctions. Neuron 24, 567-583.

Huang, E.J., Reichardt, L.F., 2001. Neurotrophins: roles in neuronal development and function. Annu. Rev. Neurosci. 24, 677-736.

Huang, Z.L., Qu, W.M., Eguchi, N., Chen, J.F., Schwarzschild, M.A., Fredholm, B.B., Urade, Y., Hayaishi, O., 2005. Adenosine A2A, but not A1, receptors mediate the arousal effect of caffeine. Nat. Neurosci. $8,858-859$.

Jacobson, K.A., van Galen, P.J., Williams, M., 1992. Adenosine receptors: pharmacology, structure-activity relationships, and therapeutic potential. J. Med. Chem. 35, 407-422.

Jarvis, M.F., Schulz, R., Hutchison, A.J., Do, U.H., Sills, M.A., Williams, M., 1989. [3H]CGS 21680, a selective A2 adenosine receptor agonist directly labels A2 receptors in rat brain. J. Pharmacol. Exp. Ther. 251, $888-893$

Katz, B., 1969. Quantal release of acetylcholine from motor nerve ending. In: The Release of Neurotransmitter Substances. Charles C. Thomas, Springfield, IL, pp. 11-12.

Kelly, S.S., 1978. The effect of age on neuromuscular transmission. J. Physiol. 274, 51-62.

Lopes, L.V., Cunha, R.A., Ribeiro, J.A., 1999. Cross talk between A(1) and $\mathrm{A}(2 \mathrm{~A})$ adenosine receptors in the hippocampus and cortex of young adult and old rats. J. Neurophysiol. 82, 3196-3203.

Mantilla, C.B., Zhan, W.Z., Sieck, G.C, 2004. Neurotrophins improve neuromuscular transmission in the adult rat diaphragm. Muscle Nerve 29, 381-386.

Menrath, R., Blackman, J., 1970. Observations on the large spontaneous potentials which occur at endplates of the rat diaphragm. Proceedings of the University of Otago Medical School 48, 72-73.

Popoli, P., Reggio, R., Pèzzola, A., Fuxe, K., Ferré, S., 1998. Adenosine $\mathrm{A} 1$ and $\mathrm{A} 2 \mathrm{~A}$ receptor antagonists stimulate motor activity: evidence for an increased effectiveness in aged rats. Neurosci. Lett. 251, 201-204.
Poucher, S.M., Keddie, J.R., Singh, P., Stoggall, S.M., Caulkett, P.W., Jones, G., Coll, M.G., 1995. The in vitro pharmacology of ZM 241385, a potent, non-xanthine A2A selective adenosine receptor antagonist. Br. J. Pharmacol. 115, 1096-1102.

Pousinha, P.A., Correia, A.M., Sebastião, A.M., Ribeiro, J.A., 2010. Predominance of adenosine excitatory over inhibitory effects on transmission at the neuromuscular junction of infant rats. J. Pharmacol. Exp. Ther. 332, 153-163.

Pousinha, P.A., Diogenes, M.J., Ribeiro, J.A., Sebastião, A.M., 2006. Triggering of BDNF facilitatory action on neuromuscular transmission by adenosine A2A receptors. Neurosci. Lett. 404, 143-147.

Ribeiro, J.A., Walker, J., 1975. The effects of adenosine triphosphate and adenosine diphosphate on transmission at the rat and frog neuromuscular junctions. Br. J. Pharmacol. 54, 213-218.

Rowley, K.L., Mantilla, C.B., Ermilov, L.G., Sieck, G.C., 2007. Synaptic vesicle distribution and release at rat diaphragm neuromuscular junctions. J. Neurophysiol. 98, 478-487.

Schiffmann, S.N., Vanderhaeghen, J.J., 1993. Age-related loss of mRNA encoding adenosine A2 receptor in the rat striatum. Neurosci. Lett. 158, $121-124$.

Sebastião, A.M., Ribeiro, J.A., 1988. On the adenosine receptor and adenosine inactivation at the rat diaphragm neuromuscular junction. Br. J. Pharmacol. 94, 109-120.

Sebastião, A.M., Ribeiro, J.A., 2000. Fine-tuning neuromodulation by adenosine. Trends Pharmacol. Sci. 21, 341-346.

Sebastião, A.M., Ribeiro, J.A., 2009. Adenosine receptors and the central nervous system. Handb. Exp. Pharmacol. 193, 471-534.

Sebastião, A.M., Stone, T.W., Ribeiro, J.A., 1990. The inhibitory adenosine receptor at the neuromuscular junction and hippocampus of the rat: antagonism by 1,3,8-substituted xanthines. Br. J. Pharmacol. 101, 453459.

Smith, D.O., 1991. Sources of adenosine released during neuromuscular transmission in the rat. J. Physiol. 432, 343-354.

Williams, M., Braunwalder, A., Erickson, T.J., 1986. Evaluation of the binding of the A-1 selective adenosine radioligand, cyclopentyladenosine (CPA), to rat brain tissue. Naunyn Schmiedebergs Arch. Pharmacol. 332, 179-183. 